\title{
A EVOLUÇÃO DO SISTEMA EDUCACIONAL BRASILEIRO E SEUS RETROCESSOS
}

ARAÚJO, Marciano Vieira de ${ }^{1}$

ARAÚJO, Marciano Vieira de. A Evolução do Sistema Educacional Brasileiro e seus Retrocessos. Revista Científica Multidisciplinar Núcleo do Conhecimento. Ano 02, Ed. 01, Vol. 1. pp 52-62, Abril de 2017. ISSN:2448-0959

\section{RESUMO}

O artigo tratará da evolução do sistema educacional brasileiro e seus retrocessos. Mostraremos um breve resgate da história da educação brasileira com as dificuldades que foram e ainda são encontradas no sistema educacional dentro das escolas públicas por um ensino de qualidade. A metodologia utilizada foi considerações das leituras de artigos e documentos estruturados para processo do sistema educacional. Temos como objetivo discutir aspectos relacionados ao delineamento de políticas públicas educacionais, considerando as ações político-administrativas e as de caráter pedagógico que ajudem os alunos no processo de ensino aprendizagem. Neste sentido, procura despertar para uma visão contextualizada e crítica dessas mudanças educacionais que revestidas de terminologias inovadoras percebidas através dos documentos oficiais, na realidade são fontes de polêmica tanto devido ao sentido das palavras na sua interpretação, quanto na eficácia da operacionalização dessas mudanças. Podemos concluir que a política educacional brasileira vem passando por adequações para garantia de uma qualidade de atendimento aos alunos em escolas comuns, mas que reformas educacionais foram traçadas para atender cada época vivenciada pela sociedade brasileira.

Palavras-chave: Sistema, Política, Alunos, Educação, Retrocessos.

\footnotetext{
${ }^{1}$ Mestrando em Educação na ANNE SULLIVAN UNIVERSITY.
} 


\section{INTRODUÇÃO}

Falar de educação brasileira é retratar a historicidade da educação com avanços e retrocessos. Nossa educação mostra no decorrer dos anos reformas educacionais, estas elaboradas para atender as necessidades da época, mas, pouco interessadas no desenvolvimento educacional.

Fazemos indagações "O que poderá ser feito para recuperar um sistema de educação básica quase falido?".

Acreditamos que, para o desenvolvimento da sociedade e do povo brasileiro, a educação precisa atingir um padrão de qualidade significativo e transformador. Afinal, nossa Constituição Federal de 1988 afirma algo parecido no artigo 205, que trata do direito à educação:

Art. 205. A educação, direito de todos e dever do Estado e da família, será promovida e incentivada com a colaboração da sociedade, visando ao pleno desenvolvimento da pessoa, seu preparo para o exercício da cidadania e sua qualificação para o trabalho.

De fato, tivemos conquista ao longo da história de nosso país. Devemos refletir, por exemplo, sobre as etapas da história brasileira que envolveram as transformações educacionais. Uma das reflexões mais profundas é a que envolve o grande número de analfabetos no Brasil, que embora os Governos venham lutando para reverter este problema, ainda não o disseminou, o que nos leva a discursão desse fato. Por que o problema do analfabetismo no Brasil ainda persiste? A deficiência educativa de nosso povo é encontrada em todos os níveis educacionais, tanto em escolas públicas quanto nas instituições particulares.

As famílias de situação econômica favorável e até mesmo profissionais da educação acreditam fielmente na educação das escolas particulares, essas pessoas têm total descrença no ensino das escolas públicas. Alguns profissionais da educação que trabalham em escolas públicas ao serem indagados o porquê de não colocarem seus filhos nessas escolas, estes justificam, não os colocam para estudar nessas 
instituições pelo motivo de se preocuparem com o futuro deles, pois precisam estar preparados. Porque esse preparo não é encontrado nas escolas públicas? Porque as escolas públicas são desacreditadas pelos próprios profissionais que nelas trabalham?

Umas das razões para que ocorra o desnivelamento dos níveis de ensino nas diferentes instituições educacionais, é a forma diferenciada que a educação foi tratada nos distintos períodos da formação de nosso povo.

Apesar dos avanços na educação brasileira, os índices de qualidade mostram-se insatisfatórios ao analisarmos rankings internacionais de educação, nos quais o País ocupa os últimos lugares. Em um ranking publicado pela Organização para a Cooperação e Desenvolvimento Econômico (OCDE), entre 76 países avaliados, o Brasil ocupa a $60^{\circ}$ posição.

Além da má qualidade educacional, que segundo a UNESCO, é o principal problema da educação no Brasil, o país sofre com a desvalorização dos profissionais da educação e a alta taxa de analfabetos - cerca de 13 milhões de brasileiros não sabem ler nem escrever, o que faz do Brasil o oitavo país com maior número de analfabetos.

Porém, apesar dos pontos negativos, o País apresenta avanços na educação. Avanços no acesso ao ensino entre a população mais pobre, a maior facilidade de acesso do ensino superior por estudantes pobres, a criação do Fundo de Manutenção e Desenvolvimento da Educação Básica e de Valorização dos Profissionais da Educação (Fundeb), além de investimentos maciços na educação, como a destinação de $75 \%$ os royalties do petróleo para a educação.

Para entender os avanços e retrocessos que ocorreram no sistema educacional brasileiro, devemos mostrar um breve histórico do modo como a educação foi tratada e os acontecimentos que influenciaram na construção do processo de ensino e aprendizagem do nosso país, bem como, os seus desafios. 


\section{A HISTÓRIA DA EDUCAÇÃO BRASILEIRA - DIREITOS, AVANÇOS E RETROCESSOS}

Com a chegada dos portugueses ao Brasil e a insubordinação dos nativos à coroa que precisava dos indígenas para a exploração do pau-brasil -, a coroa decidiu que os índios precisavam ser catequisados. Por isso, ela enviou uma missão jesuíta com o intuito de ensinar aos nativos os costumes e a religião de Portugal. O marco inicial da sistematização do ensino pode ser considerado a vinda da junta missionária católica em 1549, além disso a sistematização de transmissão de conhecimentos é indissociável da história da Companhia de Jesus.

Porém, com o fracasso da missão e a expulsão dos jesuítas em 1759, foram instauradas as reformas pombalinas, as quais instituía o ensino laico e público através das Aulas Régias - os conteúdos baseiam-se nas Cartas Régias. A data de implantação oficial do ensino público no Brasil foi em 1772, porém, o Ensino Religiosa nas escolas foi mantido.

Durante quase 300 anos da história do país, as mulheres e os escravos - oriundos da África, não tinham direito ao acesso à educação. Os homens brancos estudavam nos colégios religiosos ou iam para a Europa.

Com a vinda da família real ao país no início do século XIX, houve uma ruptura com a situação do sistema educacional anterior. Dom João VI, para preparar terreno para sua estadia no Brasil, abriu Academias Militares, Escolas de Medicina, Biblioteca Real e a Imprensa Régia. Em 1816 foi criada a Escola Nacional de Belas Artes, influenciada por artistas franceses.

Porém, a educação ainda foi tratada com importância secundária. Somente em 1909 foi criada a primeira Universidade Brasileira, a Universidade Federal do Amazonas. A USP (mais importante universidade no Brasil atualmente), foi fundada em 1934.

Já no império, a Constituição de 1824 manteve o princípio da liberdade de ensino, sem restrições, e a intenção de "instrução primária gratuita a todos os cidadãos". Em 
15 de outubro de 1827 foi aprovada a primeira lei sobre o Ensino Elementar e a mesma vigoraria até 1946 (quando a lei fracassou por motivos econômicos, técnicos e políticos). Em 1827, surge a primeira lei sobre educação das mulheres, permitindo que as mesmas frequentassem as escolas elementares, entretanto, as instituições de ensino mais adiantado eram proibidas a elas.

Em 1834 (Ato Adicional que emendou a Constituição) houve a reforma que deixava o ensino elementar, secundário e de formação dos professores a cargo das províncias, enquanto o poder central cuidaria do Ensino Superior. Em 1879 houve a reforma de Leôncio de Carvalho que propunha dentre outras coisas o fim da proibição da matrícula para escravos, mas que vigorou por pouco tempo. Em 1879, as mulheres têm autorização do governo para estudar em instituições de ensino superior, mas as que seguiam este caminho eram criticadas pela sociedade. Com a instauração da República em 1889, a educação passou por várias reformas, porém, as mudanças continuavam seguindo princípios adotados pelo Novo Regime: centralização, formalização e autoritarismo.

Durante a Primeira República, entre 1889 a 1930 foram feitas cinco reformas: a Reforma Benjamim Constant, a Reforma Epitácio Pessoa, a Reforma Rivadavia, a Reforma Carlos Maximiliano e a Reforma João Luiz Alves - de âmbito nacional do ensino secundário, com o intuito de implantar um currículo unificado para todo o país.

Até a época entre 1911 e 1915 as classes de Ensino reuniam alunos de todas as idades, além disso, o Ensino Secundário era visto como um preparatório para o Ensino Superior. Nessa época surgiu o conceito de "Grupo Escolar" (o qual reunia escolas isoladas de uma região comum). E as classes passaram a distribuir os alunos em séries, o chamado "Ensino Seriado".

A década de 1920, na área da educação, foi um período de grandes iniciativas. Foi a década das reformas educacionais. Não havia ainda um sistema organizado de educação pública, como é hoje a rede de ensino. Um dos movimentos mais importantes da época ficou conhecido com o nome de Escola Nova. Grandes temas 
e grandes figuras ficaram associados a esse movimento. A defesa de uma escola pública, universal e gratuita se tornou sua grande bandeira. Até o final da década 1920, havia quase $70 \%$ de analfabetos entre a população com mais de 15 anos de idade no país.

Em 1924 foi fundada a Associação Brasileira de Educação (ABE), que a partir de 1932 foi dominada pelos adeptos da Escola Nova.

A partir de 1930 (início da Era Vargas), surgem as reformas educacionais mais modernas. Com o Decreto 19.402 de 14 de novembro de 1930, foi criado o Ministério dos Negócios da Educação e Saúde Pública. O Ministro Francisco Campos reformou o Ensino Secundário (Reforma Campos).

Em 1932 alguns intelectuais brasileiros como Lourenço Filho, Fernando de Azevedo e Anísio Teixeira, dentre outros, assinaram o "Manifesto dos Pioneiros da Educação Nova".

Diante do mundo moderno, capitalista e que passou por uma avassaladora guerra, os intelectuais ligados à área da educação declararam insuficiência da pedagogia tradicional. Concluíram, então, que as instituições escolares deveriam ser atualizadas de acordo com a nova realidade social.

Tanto a constituição de 1934 como o manifesto de 1932 traçaram pela primeira vez as linhas mestras de uma política educacional brasileira. Contudo, a constituição de 1934 durou pouco e foi substituída pela de 1937, imposta por Getúlio Vargas. A constituição de 1934 foi a primeira a incluir um capítulo especial sobre a educação, a mesma trata da educação no seguinte artigo:

Art. 149 - A educação é direito de todos e deve ser ministrada, pela família e pelos Poderes Públicos, cumprindo a estes proporcioná-la a brasileiros e a estrangeiros domiciliados no País, de modo que possibilite eficientes fatores da vida moral e econômica da Nação, e desenvolva num espírito brasileiro a consciência da solidariedade humana. 
Em 1942, o ministro Gustavo Capanema incentivou novas leis de reforma do Ensino, que ficaram conhecidas como "Reforma Capanema". Nesse ano surgiram a Lei Orgânica do Ensino Industrial e a Lei Orgânica do Ensino Secundário, além de ter sido fundado o SENAI - Serviço Nacional de Aprendizagem Industrial. Com a lei orgânica, o Ensino Secundário foi dividido em três modalidades: Clássico, Científico e Normal (ensino profissionalizante, porém considerado dentro do ensino secundário).

Em 1937, com a implementação da ditadura varguista e a substituição da constituição de 1934, é possível perceber as consequências da organização e implementação de uma política de Estado para a educação baseado nas reformas propostas pelo Ministro da Educação Gustavo Capanema. Ocorreu um crescimento percentual das matriculas em relação à população total brasileira e também, uma diminuição relativa do analfabetismo.

Com o fim do Estado Novo, surgiu a Constituição de 1946 e que trouxe dispositivos dirigidos à educação, como a gratuidade para o Ensino Primário. Em 1948, também surgiu a discussão para uma Lei de Diretrizes Básicas, a partir da proposta do deputado Clemente Mariani. A constituição de 1946 trata da educação no seguinte artigo: "Art. 166 - A educação é direito de todos e será dada no lar e na escola. Deve inspirar-se nos princípios de liberdade e nos ideais de solidariedade humana".

Nesse período, foi implementado a Lei de Diretrizes e Bases de Educação pelo governo João Goulart. Além disso, novos debates surgiram em torno do tema educação, como a defesa dos interesses dos proprietários de escolas privadas. Nesse período, o movimento estudantil cresceu com maior atuação da União Nacional dos Estudantes (UNE).

O debate, que girava em torno da legitimação da educação privada era apoiada pelos conservadores, como o famoso jornalista Carlos Lacerda e por uma ala da Igreja Católica.

O debate em torno da Lei de Diretrizes e Bases da Educação foi retomado no Governo do Presidente Juscelino Kubitschek. Nesse contexto, é de suma importância destacar 
o papel empenhado pela Igreja Católica, que desde período colonial participava ativamente da educação no Brasil.

Entretanto, após a entrada do Estado no ensino público, a instituição anteriormente citada perdeu seu prestígio político. Por isso, além do interesse da presença/ausência do ensino religioso no currículo escolar, a Igreja também tinha interesses nos recursos públicos para a educação escolar.

Mesmo com toda campanha a favor a escola pública, as forças conservadoras, as quais tinham maior representação no Congresso, saiu vitoriosa e em 1961 foi promulgada a Lei de Diretrizes e Bases da Educação (Lei 4.024). A lei, prevaleceu o modelo de política educacional já em vigência. Nesse modelo, o Estado custeava parte das despesas das escolas particulares e não criava novas oportunidades escolares fora dos grandes centros urbanos.

Assim sendo, esse sistema estava longe de suprir as necessidades reais da população no que tange a gestão da política educacional. A pouca permanência dos estudantes brasileiros na escola e o elevado índice de analfabetismo, sobretudo no interior, foram alguns problemas não resolvidos pelo Governo, naquela época.

Após o golpe em 1964 e a implantação da Ditadura Militar, houve um aumento do autoritarismo marcado na área da educação com o banimento de organizações estudantis como a UNE - União Nacional dos Estudantes -, considerada "subversivas". Em 1969, foi tornado obrigatório o ensino de Educação Moral e Cívica em todos os graus de ensino. O Decreto 68 908/71 criou o "Vestibular Classificatório", garantindo a vaga nas universidades apenas até o preenchimento das vagas disponíveis. O Movimento Brasileiro de Alfabetização foi criado em 1967, objetivando diminuir os níveis de analfabetismo entre os adultos. A reforma dos ensinos fundamental e médio foi feita durante o governo Médici, com a Lei 5 692/71. Em 1982, a Lei 7 044/82 retirou a obrigatoriedade do Ensino Profissionalizante nas Escolas de Ensino Médio. 
Durante sua gestão, Robert McNamara (1968-1981) afirmou ser a educação uma indústria que necessitava de revolução tecnológica. Reconhecia sua necessidade básica, mas havia outros problemas. A expansão horizontal da educação como necessidade para todos e essencial para o desenvolvimento econômico, mas qualitativa para uns poucos eleitos, foi um procedimento perverso e constante. Essa política de exclusão sintomática ficou evidente quando o Banco Mundial exteriorizou as estratégias de investimentos no ensino técnico profissional e o desenvolvimento de um sistema de educação tecnológica média superior. Pretendiam, assim, instituir, através da legislação, mecanismos para deter o crescimento da demanda pelo ensino superior. (Silva, 2002: 58)

Nessa época, disciplina como filosofia foi banida do 2ํㅡ grau e outras como História e Geografia formaram aglutinadas no chamado "Estudos Sociais". E a educação superior foi restrita a uma pequena fração da sociedade.

Nessa época a escola privada ganhou forças após o Governo investir em bolsas para os estudantes, pois o ensino público não tinha cobertura suficiente, e, além disso, a evasão escolar abriu margens para as empresas privadas receberem recursos do governo para realizarem o que as escolas públicas em sua maioria não faziam - é importante salientar que as instituições privadas possuíam isenção de impostos (instituídos na Constituição de 1946 e reforçado nas emendas promulgadas durante a ditadura militar). Por isso, pode-se concluir que o dinheiro que poderia ser investido na ampliação e expansão do ensino público foi destinado ao empresariado.

É marcante, nessa época, as lutas contra a censura por parte dos estudante e intelectuais. A UNE, que foi banida, atuou de forma clandestina contra a Ditadura Militar, organizando protestos contra o governo entre outras coisas. Alguns professores universitários e outros intelectuais (pessoas ligadas a jornais, a arte, a música, advogados e até mesmo políticos), também atuaram de forma clandestina e sutil para driblar a censura imposta pelo regime. 
Após o regime militar, e a retomada da democracia no final da década de 80 , a educação mereceu destaque na Constituição Brasileira de 1988, que em seus dispositivos transitórios dava o prazo de dez anos para a universalização do Ensino e a erradicação do analfabetismo.

Ainda em 1996 surgiu a nova LDB - Lei das Diretrizes Básicas, que instituiu a Política Educacional Brasileira. Nessa época, também foi criado o Conselho Nacional de Educação, substituindo o antigo Conselho Federal de Educação que havia surgido em 1961 e havia sido extinto em 1994.

Em 1996, foi criado o FUNDEB (Fundo de Manutenção do Ensino Fundamental) que depois de dez anos foi substituído pelo FUNDEF, que obriga os Estados e Municípios a aplicarem anualmente um percentual mínimo de suas receitas onde $60 \%$ pelo menos é para pagamento do pessoal do magistério. Em fevereiro de 2006, foi aprovada a lei № 11.274 , que aumentou a duração do ensino fundamental de oito para nove anos.

Atualmente, vivemos a era da educação. Nunca na história do país foi investido tanto dinheiro a educação como agora. Porém, esse dinheiro pode estar sendo mal administrado. Além de casos de corrupção que são noticiados em todo o país envolvendo a educação.

Antigamente, era difícil o acesso à educação por parte de famílias pobres. Essas famílias que dependiam do ensino público, esperavam em filas enormes para conseguir efetuar a matricula de seus filhos. Atualmente, sobram vagas para o ensino básico. Além disso, com o aumento de escolas, as instituições estão cada vez mais perto dos alunos, antigamente era preciso de uma longa viagem para chegar na escola.

O século $X X I$, foi tomado por uma discursão polêmica em torno da educação e tecnologia. O mundo globalizado, precisa de trocas de informações cada vez mais rápida, por isso, as novas tecnologias como os 'smartphones', os 'tabletes' já invadiram a sala de aula de diversas instituições. 
Outras questões polêmicas na atualidade, e que prejudica o nível e a qualidade da educação, é a chamada "Mercantilização da Educação". Faculdades Particulares com péssima qualidade educacional oferecem meios fáceis de acesso ao nível superior. Como essas faculdades "aprovam" os alunos com o receio de perder o aluno e consequentemente a mensalidade, o nível de qualidade dos profissionais está cada vez mais diminuindo.

Além disso, o governo injeta milhões de dinheiro no ensino público através de programas como o Pro Uni (O Governo paga a mensalidade do aluno em uma instituição privada), dinheiro esse que poderia está sendo investido na educação superior pública. Essas faculdades, tem nível muito abaixo das universidades públicas, então se o governo ampliasse a oferta de matriculas nas instituições públicas, não era preciso pagar mensalidades em instituições privadas com ensino inferior ao ensino superior público.

Porém, é necessário ressalta que, de fato, o acesso ao nível superior em universidades públicas tornou-se mais dinâmico. A Lei $n^{\circ} 12.711$, denominada "Lei das Cotas", garante $50 \%$ das vagas das universidades públicas aos estudantes de escola pública.

Essa problematização a respeito do tema se deu ao perceber as características sociais/econômicas/financeiras de estudantes do nível superior no passado. Acontece que esses estudantes sempre tiveram a oportunidade de ter ensino de qualidade (melhor que o ensino público), pagar cursinhos particulares e até mesmo poderiam pagar a "mensalidade" da universidade. Por isso, os estudantes do ensino público não tinham como competir por uma vaga com os estudantes do ensino privado.

Após a apresentação de ideias sobre a gerência da Educação Pública no país, desde o descobrimento aos dias atuais tivemos a chance de refletir acerca dos avanços e retrocessos da educação brasileira. 
Analisamos os problemas sociais que refletem negativamente no desenvolvimento da Educação do país, como a vergonhosa distribuição de renda do Brasil, que impede que os discentes se dediquem como deveriam em seu processo de aprendizagem.

$\mathrm{Na}$ verdade, o que interessa são as estatísticas apresentadas no exterior, o quantitativo de crianças dentro da instituição de ensino, mas, infelizmente ainda temos um grande número de analfabetos em nosso país. Contudo, tais números relatam a vexatória qualidade da nossa educação pública, onde os professores são mal remunerados e desrespeitados, as crianças não possuem uma estrutura emocional apropriada para desenvolverem-se expressivamente e os aumentos consideráveis da criminalidade no Brasil, vem reforçar que precisamos urgentemente de uma estrutura educacional mais eficaz para que a educação brasileira transforme nossa sociedade.

\section{CONSIDERAÇÕES FINAIS}

A falta de uma política educacional adequada dentro dos padrões da realidade social, resultado do descaso e descomprometimento dos órgãos públicos para com a sociedade, tem como resultado nefasto e lastimável, a inclinação das crianças e jovens para marginalização, este fato é o resultado do atual quadro social brasileiro.

Alguns avanços no sistema educacional brasileiro devem ser ressaltados, mas que são mínimos e imprecisos diante da urgente necessidade de mudanças que o país necessita. Como exemplo, podemos citar o avanço com relação à obrigatoriedade, pois a política de conscientização junto aos responsáveis e, mormente a ameaça com respeito à perda da guarda, conseguiram diminuir o número de crianças fora da escola.

Outro progresso que merece ser enfatizado diz respeito ao atendimento a jovens de 15 e 17 anos. Através dessa iniciativa, muitos jovens e adultos estão voltando à escola e conseguindo desenvolver-se intelectual e profissionalmente.

Devemos acreditar na possibilidade de transformação da sociedade através da Educação. Mas, a burocracia está intrínseca ao Sistema Educacional, impedindo 
assim, qualquer desenvolvimento da sociedade. Burocracia essa que não passa de um instrumento do sistema capitalista, respaldado pela burguesia, que não está interessada em mudanças substantivas no pensamento da massa populacional. Seria inconsequente afirmar que a educação não auxilia o indivíduo no seu convívio na sociedade, mas é inegável que a classe dominante utiliza as diretrizes educacionais do país, objetivando defender os seus próprios interesses e manter os seus privilégios.

\section{REFERÊNCIAS}

ARCE, Alessandra O Mobral e a Educação de Crianças Menores de Seis Anos durante o Regime Militar: Em Defesa do Trabalho Voluntário in Caderno Cedes, Campinas, vol. 28. (Disponível em http://www.cedes.unicamp.br)

BRITO, Vera Lúcia Alves de. O público, o privado e as políticas educacionais.

CONCEIÇÃO, Gilmar Henrique da. Partidos políticos e educação: a extrema esquerda brasileira e a concepção de partido como agente educativo. Cascavel: Edunioeste, 2000.

DUARTE, Maria R. T. (Org.). Política e trabalho na escola: administração dos sistemas públicos de educação básica.

Fonte: Lourenço Filho, Evolução da Taxa de Analfabetismo de 1900 a 1960, RBE, ํo 100 .

Fonte: Romanelli, Otaíza História da Educação no Brasil (1930 - 1973) Petrópolis, Vozes, 2008.

FREITAG, Bárbara. Escola, Estado e Sociedade. São Paulo: Moraes, 1986.

Pelo fim das décadas perdidas: educação e desenvolvimento sustentado no Brasil, Texto para discussão № 857. (Disponível em http://www.ipea.gov.br, 2002.)

Portal INEP - Instituto Nacional de Estudos e Pesquisas Educacionais Anísio Teixeira. 
Revolução na escola Educar para Crescer. 